\title{
Names and geography
}

\author{
Gammeltoft, Peder
}

Published in:

The Oxford Handbook on Names and Naming

DOI:

10.1093/oxfordhb/9780199656431.013.58

Publication date:

2016

Document version

Publisher's PDF, also known as Version of record

Document license:

Unspecified

Citation for published version (APA):

Gammeltoft, P. (2016). Names and geography. In C. Hough (Ed.), The Oxford Handbook on Names and Naming: Oxford Handbooks in Linguistics (pp. 502-513). Oxford University Press.

https://doi.org/10.1093/oxfordhb/9780199656431.013.58 


\section{Oxford Handbooks Online}

\section{Names and Geography a}

Peder Gammeltoft

The Oxford Handbook of Names and Naming

Edited by Carole Hough

Print Publication Date: Jan 2016 Subject: Linguistics, Semantics, Pragmatics

Online Publication Date: Mar 2016 DOI: 10.1093/oxfordhb/9780199656431.013.58

\section{Abstract and Keywords}

Place-names and geography are closely connected. It is impossible to understand either discipline without some knowledge of the other. Place-names should be seen as the spoken expression of humans' view of the surrounding landscape, thus acting within both physical and human geography, in as much as place-names describe aspects both of the natural world and of human created space. One of the challenges in using place-names in connection with geography is to establish when a name was established and the significance of the naming focus. In addition, later onomastic developments may create a mismatch between current denotation and the original place-name meaning. Since placenames may tell us about geography at the time of naming, they are excellent in teasing out information about past geographical realities. In recent years, Geographical Information Systems and geospatial databases have come to play a greater role in both onomastic research and geography.

Keywords: place-names, geography, human geography, physical geography, Geographical Information Systems, geospatial information, place-name databases

Just as all phenomena exist in time and thus have a history, they also exist in space and have a geography.

(United States National Research Council, 1997)

\subsection{Introduction}

PLACE-NAMES and geography are closely interlinked-understanding of either discipline cannot be carried out without some knowledge and use of both. In many cases, placenames can be seen to be the spoken expression of Man's view of the surrounding 
landscape. Although many geographers are trained in toponymy, this is not necessarily a focal preoccupation. Geographers study spatial and temporal distribution of phenomena, processes, and features. In addition, the interaction of humans with their environment is also a main study area. Because the study of geography concerns a number of disciplines - such as economics, health, climate, plants, and animals-geography is a very interdisciplinary science, with close attention to the relationship between physical and human phenomena and its spatial patterns.

Geography as a discipline can be split broadly into two main subsidiary fields: human geography and physical geography. Human geography largely focuses on how humans create, view, manage, and influence space. It is a branch of geography that focuses on the study of patterns and processes that shape human society. It encompasses the human, political, cultural, social, and economic aspects. Physical geography, on the other hand, examines the natural environment, and how organisms, climate, soil, water, and landforms produce and interact. The focus is on geography as an Earth science. It aims to understand the physical problems and the issues of lithosphere, hydrosphere, atmosphere, pedosphere, and global flora and fauna patterns (biosphere).

The combination of both fields is known as environmental geography-focusing on interactions between the environment and humans. This brand describes the spatial (p. 503) aspects of interactions between humans and the natural world. It requires an understanding of the traditional aspects of physical and human geography, as well as the ways in which human societies conceptualize the environment.

Environmental geography has bridged human and physical geography, and has partly arisen as a result of the change in human relationship with the environment-as a result of globalization and technological change. Thus, a new approach was needed to understand the changing and dynamic relationship between Man and the natural world. Examples of areas of research in environmental geography include emergency management, environmental management, sustainability, and political ecology. Further subdivisions exist, including urban planning, regional planning, and spatial planning. These branches use the science of geography to determine how to develop (or not develop) a region in order to meet particular criteria, such as safety, beauty, economic opportunities, the preservation of the built or natural heritage, and so on.

\subsection{Place-names as Expressions of Geography}

Place-names act within both physical and human geography, in as much as they describe aspects of both the natural world and human created space at around the time of naming. 
One of the challenges in using place-names in connection with geography are to establish when a name was coined and the significance of the naming focus. Another main challenge lies in later onomastic developments, which, through metonymical processesfor example a place-name comes to signify a different type of locality from the one it originally did-create a mismatch between the current denotation and the original placename meaning. In the case of metonymy, it can often be difficult to single out the original name bearing or name originating locality, and a certain amount of qualified guesswork frequently has to be applied in singling out the original name bearer.

The geographical aspect is usually most clearly expressed in the generic element of place-names, as their function within the name is to state what type of locality the name concerns. Thus, any place-name with a generic in -grad, -stadt, -ville, and Baille- will normally denote some kind of conglomerated settlement ranging from a group of buildings to a village or town. In the same way, a name in -bosch, -skov, or -wood would originally have denoted a coherent area consisting almost exclusively of trees. In this respect place-names act as an intermediary between present and past geographical realities. Place-names usually denote localities of today, which may or may not be the same as the original denotation. However, in terms of the meaning carried in the placename expression, the place-name describes a perceived state of geography at the time of naming - a situation which may be radically different from what can be observed today. For instance, the name Werningerode (1122 Werniggerode, Werningerode) in Harzen, (p. 504) Germany, originally denoted a clearing (Middle High German rot 'clearing') (Eichler and Walther 1986: 20), that is, a brief geographical state of pointing to an area affected by the human activity of tree-felling (Eichler and Walther 1986: 292-3). Here we have embedded in the name an instance of human intervention with physical geography. In relation to the current denotation of Werningerode as a town situated between Harzen and Magdeburg, there is no correspondence whatsoever. Nonetheless, it can be speculated, through the place-name's original denotation, that this town was established as a result of woodland having been cleared.

It should be mentioned, however, that some types of place-names are not capable of expressing geographical content. The most common type of place-names in this category are derivations, that is, place-names formed by adding a suffix to a word in existence at the time of naming. To the north-east of the above-mentioned Werningerode, we find the name of Gröningen (905 Gronigge, 934 Groninga, 961 Gruoningi) which is an -ingi/-inga derivation of Old Saxon grōni 'green' (Eichler and Walther 1986: 24-5, 120). In this case, the name is only capable of conveying that something is akin to 'green', but not what it is, be it landscape, people, or perceived qualities. In addition, a few generic elements do not relate to geography but to societal factors, particularly aspects of ownership, purchase, or inheritance. This is the case for instance with Gröningen's neighbouring town, 
Hadmersleben (963 Hathumereslevu, 994 Hadumereslevu) (Eichler and Walther 1986: 127), a place-name in German -leben, which, like its Danish and Swedish counterparts in lev and -löv (Søndergaard 1972: 158-80), derive from Common Germanic laiba 'inheritance' (Eichler and Walther 1986: 19). The naming thus concerns an act between people, the act of leaving something to another person or receiving something from someone else. It is very telling that the vast majority of this name type features late Iron Age personal names and titles as specifics, something which is also seen in later names in -køb/-köp 'purchase' in Southern Scandinavia. Here names such as Basseköp (1499 Bassekøp), Høsterkøb (1185-87 Husfrecop, 1193 Husfrekop, c.1370 Husfrwkøp), and Svensköp (1377 Swensskip, 1390 Suenskøb), describe how they were purchased by Bassi, the wife (< Danish hustru 'wife, spouse') and Svend, respectively. Again, central to the naming is a transaction between people, a purchase.

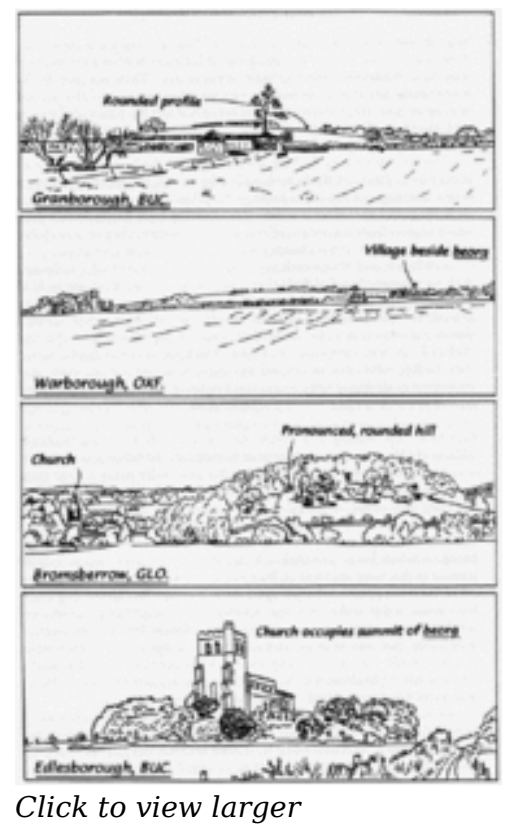

Figure 35.1 Sketch map from Gelling and Cole (2000: 248), showing landscape representations of OE beorg.

Reproduced by kind permission of the author.
How precise then is the geographical aspect in names? Many of the words used in place-names have a general meaning in language, but several studies have indicated that place-name elements can have a more specific meaning than they have as ordinary words. For instance, Gelling and Cole (2000: 145-8) have shown that the Old English word beorg 'hill, mountain' in place-names carries the meaning 'rounded hill, tumulus', occasionally 'a rounded knob at the end of a ridge', where the central

characteristic element is a continuously rounded profile and a smallish size, see Fig. 35.1. Gelling and Cole (2000) admit that it has not been possible to fit this appearance to all places with beorg as the generic element. And, indeed, it is possible that the meaning may differ geographically. This is what Mølgaard (2012: 73-81) has shown in her study of the Danish cognate bjerg in central Jutland. In Danish, the word connotes an (p. 505) 'elevation' in general, but in Mølgaard's (2012) study, the place-name element bjerg 
tended to denote either: (a) a 'rounded or cone-shaped elevation', prevalent in the western and central parts of central Jutland, a meaning akin to Gelling and Cole's central meaning, (b) 'an elevation of ness-like character', predominant in the western parts of the research area, or (c) an 'elevation on the edge of a plateau', found (p. 506)

throughout the research area and relatively similar to Gelling and Cole's (2000) second definition of 'a rounded knob at the end of a ridge'. In addition, there was also a small number of names in -bjerg which could not be classified. The unexpected result of Mølgaard's (2012) research was that the element bjerg was predominant in the western parts of her study area, central Jutland. This is surprising, as this part of the country is known to be the least elevated in Denmark. In addition, the fact that several types of denotations could be singled out in, partly, differing areas also shows how place-names tend to merge with local landscape and take on meanings found in the local geography. Thus semantics and landscape morphology become closely interlinked in such a way that an element like Danish bjerg, whose Common Germanic meaning is that of 'mountain', may end up denoting smallish elevations in a landscape barely rising 30-40 metres above sea level.

\subsection{Place-names as Indicators of Former Landscape}

Man has had a profound effect on geography. For instance, most of the acreage of Western Europe has over the centuries been transformed into arable land at the cost of forests, meadows, and the reclamation of land from seas and fjords. Again, a lot of the arable land has later been given over to urbanization as the world's population has grown at ever increasing rates at the same time as billions of people have migrated from rural areas to urban centres in the latest century or so, a tendency which is forecast to increase over the next decades.

Greater London, as an example, now covers $1,579 \mathrm{~km}^{2}$, and houses in the region of 8 million people. It goes without saying that the geographical transformations in terms of housing and infrastructural developments are enormous and the current geographical reality in Greater London is completely different from a century, let alone a millennium, ago.

In many cases, place-names can give an indication of the earlier geographical states of areas that have undergone substantial human geographical changes. In that respect, the Greater London District of Wandsworth (eleventh-century Wendleswurthe), whose 
generic derives from Old English (OE) worb 'homestead' (Ekwall 1947: 510-11; Mills 2001: 239), shows that this area was once home to an Anglo-Saxon settlement. In fact, when including the other places within this district, we get a picture of an area overwhelmingly Anglo-Saxon in character. Not only do we have original landscape denoting names such as Battersea (693 Badrices ege, Batrices ege), sporting a generic in OE $\bar{e}$, iēg 'island' (Mills 2001: 14-15), but also human geography related names such as Balham (957 Bolgenham, from OE hām 'village, estate, manor, homestead'), Putney (1086 Putelei, 1279 Puttenhuthe, from OE hȳb 'landing place'), and Roehampton (1350 (p. 507) Rokehampton, from OE hämtūn 'home farm, central estate') (Ekwall 1947: 203, 206; Mills 2001: 9, 184, 192). In general the place-names of Wandsworth, in terms of etymology, convey a picture of a rural, agricultural area, reflecting a geographical situation from, possibly, as early as the fifth-sixth centuries and onwards. The current associations of the district, with its former wharf area on the river-front now lined with new apartment blocks, bars and, restaurants, its recently regenerated Southside shopping centre, and housing developed over the centuries for immigrants seeking their luck in London, could not be much further removed from this. Instead, the place-names of Wandsworth have now come to signify urbanism and aspects of London life.

Even in less changed environments, place-names may help to reconstruct former geographical realities. In a study from 2006, Gammeltoft and Egeberg have shown how field names may help to pinpoint lost burial mounds and, thus, reconstruct ancient communication routes (Gammeltoft and Egeberg 2006). It has long been observed that burial mounds in Denmark often follow ancient roads and tracks (Müller 1904: 1-64; Egeberg 2004: 44-51), something which is most clearly observable in West Jutland where extensive farming is a relatively recent phenomenon. Thus, a significant number of burial mounds have avoided being removed to make way for farming, and those which have been removed are to a large extent still localizable in the surface soil or on cadastral maps from the turn of the nineteenth century, see Fig. 35.2.

In the early 2000s a project, Høj og Vad Projektet (the Mound and Ford Project), registering grave mounds and ancient fords in West Jutland, had localized several thousand mounds and a significant number of fords in an area of $25 \times 40 \mathrm{~km}^{2}$

(Gammeltoft and Egeberg 2006: 15). In this way, a number of hitherto unknown ancient roads were uncovered, as mounds lining the roads made it possible to reconstruct the routes exactly and fords showed where the routes crossed watercourses. One problem was, however, to connect the routes visible by means of lines of mounds to the registered ancient fords, as there was often an area of 'blank' land between mounds and fords. It was discovered that the areas void of mounds constituted areas of longstanding cultivation where mounds would have been removed much earlier. 


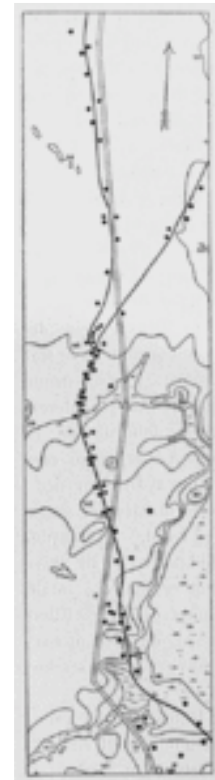

Click to view larger

Figure 35.2 Map from Müller (1904: 18), showing the distribution of Bronze Age mounds running along ancient roads
However, by consulting local place-names, particularly field names, it was possible to locate a significant number of lost mounds. These were identified through the form -høj 'mound, hill'. In addition, some names indicating roads and paths were also located. In this way, it was possible to reconstruct the missing stretches of roads in the arable between the less intensively cultivated land and fords. The localization of ancient roads will naturally be less precise

when dealing with field names alone, as the field names themselves define a much looser localization in as much as they state that a piece of land is related to a mound-either by having a mound in the field or by being situated next to a mound. In reality, however, the localization proved precise enough to provide a general impression of the ancient route, see Fig. 35.3. (p. 508) 


\subsection{Geospatial Technology and Place-names}

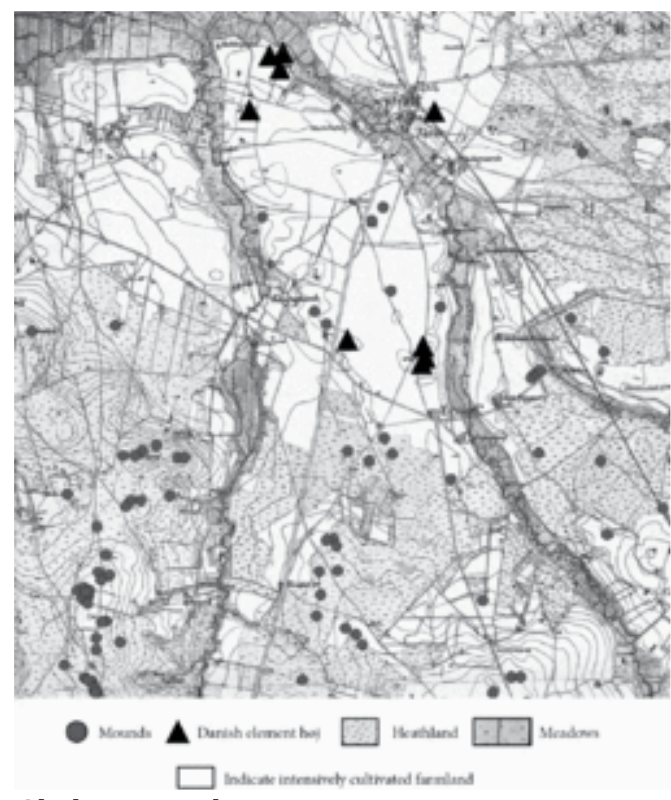

Click to view larger

Figure 35.3 Map of northern Egvad parish from 1871. The map is marked with black circles indicating known mounds; black triangles indicating place-names containing the Danish element -høj
With the increasing digitization of geospatial data, place-names are being looked upon with increasing interest from geospatial management organization. ${ }^{1}$ The interests span (p. 509) from creating reliable transnational place-name data, through making such data publicly available, to ensuring regional or universal standards. The rise in focus on high quality place-name data is mainly technology-drivenit has simply become much easier to utilize online

geospatial data for private and public users over the last few years. Geospatial data is no longer solely of national interest but of international importance.

(p. 510) With the rise of Geographic Information Systems (GIS) in the 1980s, desktop analyses of geospatial data became available for a wider audience and complex modelling of geography, geology, and social and cultural conditions has grown explosively since the 1990s. However, the use of GIS in place-name research has often been little but distribution maps of specific place-name types, sometimes in combination with analyses of soil conditions, surface geology, and the like. ${ }^{2}$ Spatial data exist either as licensed data or open source, as download or online via web services. ${ }^{3}$ Place-name data has traditionally, bar a couple of notable exceptions, ${ }^{4}$ been licensed products-although more and more countries are releasing place-name datasets as open source.

The major problem with GIS datasets is that it has not been easy to publish point, line, or polygon data on the internet. This has to some extent been remedied by the establishment of the KML-data standard which allows the viewing of geospatial data directly online on GoogleEarth, GoogleMaps, Open Street Map, etc. So far, this 
technology is somewhat restricted in comparison with GIS software but works well for displaying place-name data in the form of places, lines (e.g. roads and rivers), and areas (e.g. administrative or historical divisions). However, the development of browser-based GIS software is currently exploding, with numerous solutions available (at cost) already. These products are generally still lacking somewhat in features in comparison to desktop GIS programs.

\subsubsection{Place-name Databases}

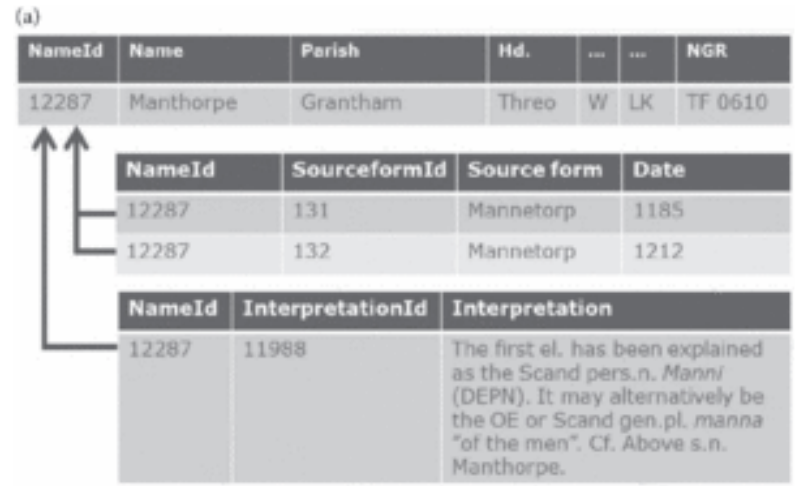

Click to view larger

Figure 35.4a Relational database structure

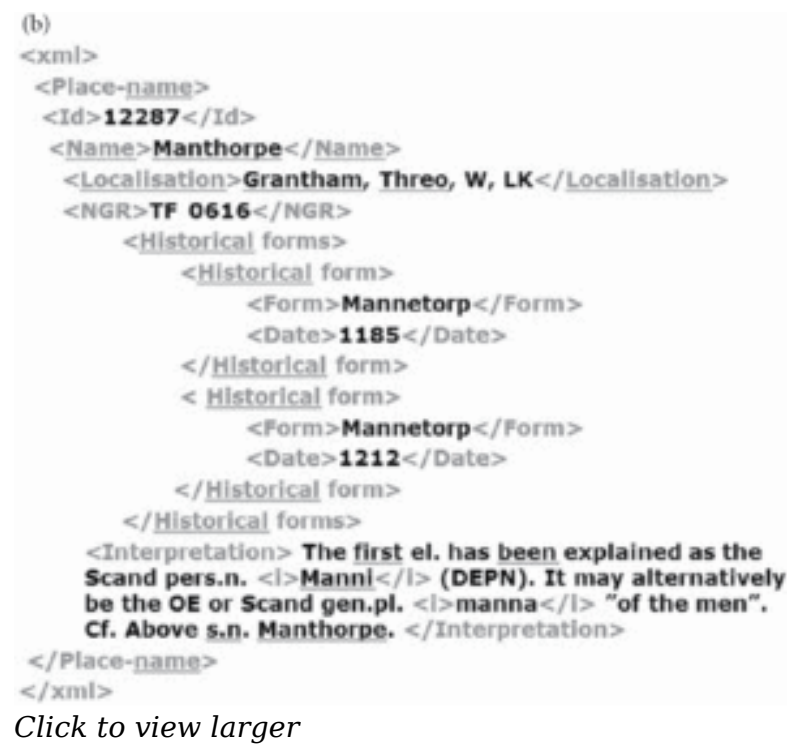

Click to view larger

Figure 35.4b Hierarchical database structure
Place-name datasets have become a central component of GPS navigation systems and online maps, ${ }^{5}$ and are widely used in scientific research. There are, however, often notable differences between geospatial place-name datasets and scientific place-name datasets-the former often being singletable datasets with coordinate information, ${ }^{6}$ in addition to place-name, feature type, and administrative information. Scientific (p. 511) place-name datasets are often multitabular, ${ }^{7}$ displaying current and historical name forms as well as interpretations and etymology for individual place-names, but not

necessarily coordinate information, see Fig. $35.4 .^{8}$ A combination—or merger-of the two data types will yield considerable benefits for both usages, though. 


\section{(p. 512) 35.4.2 International Onomastic-geospatial Initiatives}

With more and more place-name data becoming available to single users and data use becoming international and universal, the need for international standards is growing. Several initiatives exist for the management of geospatial data, including place-name data, such as the EU-initiated EuroGeoNames ${ }^{9}$ and the INSPIRE Directive. ${ }^{10}$ At an international level, the United Nations has two initiatives: UNGEGN ${ }^{11}$ and GGIM. ${ }^{12}$ Of these, UNGEGN is a place-name specific initiative, such as EuroGeoNames, whereas the GGIM and INSPIRE span all aspects of geospatial data.

\section{Notes:}

$\left({ }^{1}\right)$ An early example of widely available geospatial data put in use in online applications is postal information (usually post codes and addresses). The availability of such datasets has meant that it is often easier to find a location by means of a post code or a specific address than by means of a place-name. However, from a user's point of view, placenames are much more usable than specific addresses, and particularly post codes. After all, how many would actively search for the postal code 6240 and not Løgumkloster (Denmark) in order to seek out the location of this town?

$\left({ }^{2}\right)$ The most common GIS systems are licence-only ArcGis and MapInfo. Lately, however, initiatives like the Open Geospatial consortium, with resulting open GIS standards, have resulted in an array of free or low-cost GIS software.

${ }^{3}$ ) Normally in the form of a either (1) a Web Map Service (WMS), a standard protocol for serving georeferenced map images over the internet generated by a map server using data from a GIS database, or (2) a Web Feature Service Interface Standard (WFS) providing an interface allowing requests for geographical features across the web using platform-independent calls. The WMS/WFS specifications is developed and published by the Open Geospatial Consortium.

$\left({ }^{4}\right)$ Such as the US based GeoNames.

$\left({ }^{5}\right)$ Such as GoogleEarth, GoogleMaps, Bing Maps, Open Street Map, and national versions, e.g. the British OS VectorMaps, etc. Place-name datasets also have potential interest for the so-called Augmented Reality technology, currently pioneered by smartphone-applications such as Layar and Wikitude.

$\left({ }^{6}\right)$ Normally either in latitude/longitude or the international WGS 84 system. The open KML-standards as promoted by Google use latitude and longitude coordinates, whereas 
GeoNames feature both standards. GIS software is usually capable of working with a wide array of coordinate systems.

$\left({ }^{7}\right)$ Normally in the form of relational databases in SQL formats or in semi-structured datasets based on the XML standard or the like.

$\left.{ }^{8}\right)$ The latest in database development is the so-called open structure databases, usually in $\mathrm{xml}$ or JSON format where data are not stored in individual and specially designated data fields but more or less as text as in a word-processing document. Although heralded as the next big thing, for place-name purposes-where we often operate with several names of exactly the same form-the immediate benefits of non-tabular data aggregation is easily lost to the need for tagging of data in order to assure correctness.

$\left({ }^{9}\right)$ EuroGeoNames is a branch of EuroGeographics (<http://www.eurogeographics.org/>, whose activities focus on underpinning the European Spatial Data Infrastructure INSPIRE). EuroGeoNames combines Geographic Names from the National Mapping and Cadastral Agencies across Europe to create a unique open-access service and data set. EuroGeonames aims to provide significant benefits for public, private, and personal use by enabling place-name data suppliers to provide geo-referenced location information by providing: (1) reliable, high quality, comprehensive geographic names from official sources; (2) translation for place-name data into 25 languages; (3) easy access to updates; (4) a service-based infrastructure for collection and delivery of data; (5) a web interface that allows simple, live search and reference in all languages.

$\left({ }^{10}\right)$ INSPIRE $(1995-2015)=$ Infrastructure for Spatial Information in the European Community. The INSPIRE directive aims to create a European Union spatial data infrastructure to enable the sharing of spatial information among public sector organizations and secure public access to spatial information across Europe. The spatial information under the directive is extensive with a great variety of topical and technical themes. INSPIRE is based on a number of common principles: (1) data should be collected only once and kept where it can be maintained most effectively; (2) spatial information must be possible to combine seamlessly from different sources across Europe and be used by many users and applications; (3) data should be available at all levels or scales irrespective of level/scale of collection; (4) geographic information needed for good, all-level governance should be readily and transparently available, and (5) easy to find what geographic information is available, how it can be used to meet a particular need, and under which conditions it can be acquired and used.

(11) UNGEGN = United Nations Group of Experts on Geographical Names, is one of seven expert-groups under the UN's Economic and Social Council (ECOSOC) which provide technical recommendations on standardizing geographical names at national and 
international levels. Conferences are held every five years under United Nations Conferences on the Standardization of Geographical Names (UNCSGN), whereas UNGEGN meets bi-annually between the Conferences to follow up the implementation of resolutions adopted by the Conferences and to ensure continuity of activities between Conferences. Today, UNGEGN has more than 400 members from over 100 countries. Outside its meetings, UNGEGN functions through 23 geographical/linguistic divisions and through working groups, currently addressing issues of training courses, digital data files and gazetteers, romanization systems, country names, terminology, publicity and funding, and toponymic guidelines.

(12) GGIM = United Nations initiative on Global Geospatial Information Management, a geospatial initiative which aims to play a leading role in setting the agenda for the development of global geospatial information and promoting its use to address key global challenges. It provides a forum to liaise and coordinate among Member States, and between Member States and international organizations.

\section{Peder Gammeltoft}

Peder Gammeltoft has researched place-names since 1996, focussing on place-names of Scandinavian origin outside of Scandinavia. His major contributions include a survey of the Old Norse place-name element bólstaðr, regional studies of placenames containing Old Norse tóft in the former Viking-Age colonies, island names, and managing the digitization of the Danish place-name collections. He also takes an active part in the standardization of place-names through the Danish Place-Name Commission and UNGEGN.

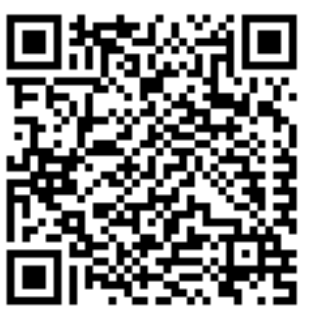

